\title{
Research Letter \\ Correlation between the Bulk Modulus and the Metallicity in Semiconductors
}

\author{
Y. Al-Douri \\ Laboratoire CRISMAT, ENSICAEN, CNRS UMR 6508, 6 Boulevard du Maréchal Juin, F-14050 Caen Cedex, France
}

Correspondence should be addressed to Y. Al-Douri, yaldouri@yahoo.com

Received 15 July 2007; Accepted 5 October 2007

Recommended by D. Zhang

The metallicity in semiconductors with respect to energy gap along $\Gamma \rightarrow \mathrm{X}$ is used to calculate bulk modulus and gives reasonable results in agreement to that of experimental and Cohen results.

Copyright ( $) 2007$ Y. Al-Douri. This is an open access article distributed under the Creative Commons Attribution License, which permits unrestricted use, distribution, and reproduction in any medium, provided the original work is properly cited.

\section{INTRODUCTION}

It has become possible [1] to compute structural, thermal, and other static properties knowing only the atomic numbers and masses of the atoms composing the materials. The transforming of a qualitative or verbal concept into a quantitative or mathematical formula represents the difficulty in defining the bulk modulus. More empirical approaches have been developed [2] with yield analytic results which can be used for exploring trends in materials properties. Because ab initio calculations are complex and consuming time, more empirical approaches have been developed $[2,3]$ to compute properties of materials. In many cases, the empirical methods offer the advantage of applicability to a broad class of materials and illustrate trends. These empirical approaches do not give highly accurate results for each specific material, but they are still very useful. Cohen [4] established an empirical formula for the calculation of the bulk modulus, based on the nearest-neighbor distance. His result is in agreement with experimental scale.

In this paper, we have established an empirical formula for the calculation of the bulk moduli $B_{0}$ of a specific class of materials. The theory yields a formula with three attractive features. Due to approaching their values and treating them as a common characteristic for the zinc-blende crystals, only the metallicity $\alpha_{m}$ and the energy gap along $\Gamma \rightarrow \mathrm{X}$, respectively, are required as input, the computation of $B_{0}$ itself is trivial. This option is attractive where it allows the consideration of hypothetical structure and the simulation of exper- imental condition that are difficult to achieve in the laboratory, for example, very high pressure.

\section{RESULTS AND DISCUSSION}

The goal of this study is to understand how qualitative concepts, such as bulk modulus, can be related to metallicity. This calculation is based upon metallicity $\alpha_{m}$ which has been reported previously [4-10]. An important observation for studying $B_{0}$ is the clear difference between the metallicity going from the group-IV to III-V and II-VI semiconductors as seen in Table 1. Hence, the metallicity is predominantly dependent on $B_{0}$. A likely origin for the above result is the increase of ionicity and loss of covalency with the same chain. Because of the smaller contribution of covalency to $B_{0}$, it is probably the increase of ionic bond charge that will reduce $B_{0}$. Hence, the ionic contribution to $B_{0}$ is of the order 40 to $50 \%$ smaller. The differences between the metallicity and bulk moduli and the later reflects of the hardness of the materials have led to consider this model.

The basis of this model is the metallicity as seen in Table 1 . The fitting of these data gives the following empirical formula:

$$
B_{0}=(60-\lambda 20)\left[\frac{E_{g \Gamma \mathrm{X}}}{\alpha_{m}}\right],
$$

where $\alpha_{m}$ is the metallicity in $(\mathrm{eV}), E_{g \Gamma \mathrm{X}}$ is the energy gap along $\Gamma \rightarrow \mathrm{X}$ in $(\mathrm{eV}), \lambda$ is a parameter appropriate for the group-IV $(\lambda=0)$, III-V $(\lambda=2)$, and II-VI $(\lambda=2.65)$ semiconductors, and the first term is in (GPa). The calculated bulk 
TABLE 1: The calculated bulk moduli along with those of experimental and Cohen [4] values, corresponding with metallicity and energy gap $E_{g \Gamma X}$ in $(\mathrm{eV}) .{ }^{\mathrm{a}}[4],{ }^{\mathrm{b}}[5],{ }^{\mathrm{c}}[6],{ }^{\mathrm{d}}[7],{ }^{\mathrm{e}}[8],{ }^{\mathrm{f}}[9],{ }^{\mathrm{g}}[10]$.

\begin{tabular}{|c|c|c|c|c|c|}
\hline Compound & $B_{0}$ cal. $(\mathrm{GPa})$ & $B_{0}$ exp. $(\mathrm{GPa})$ & $B_{0}[4](\mathrm{GPa})$ & $\alpha_{m}[3]$ & $E_{\text {gГХ }}(\mathrm{eV})$ \\
\hline $\mathrm{Si}$ & 100.9 & $98^{\mathrm{a}}$ & 98 & 0.66 & $1.11^{\mathrm{e}, \mathrm{f}}$ \\
\hline $\mathrm{GaP}$ & 74.19 & $87^{\mathrm{a}}$ & 87 & 0.62 & $2.3^{\mathrm{g}}$ \\
\hline InP & 66.6 & $67^{\mathrm{a}}$ & 67 & 0.63 & $2.1^{\mathrm{g}}$ \\
\hline $\mathrm{AlSb}$ & 58.8 & $58^{\mathrm{a}}$ & 57 & 0.68 & $2.0^{\mathrm{g}}$ \\
\hline GaAs & 73.23 & $74.8^{\mathrm{b}}$ & 77 & 0.71 & $2.6^{\mathrm{g}}$ \\
\hline InAs & 59.15 & $60^{\mathrm{a}}$ & 61 & 0.71 & $2.1^{\mathrm{g}}$ \\
\hline $\mathrm{GaSb}$ & 56.7 & $57^{\mathrm{a}}$ & 58 & 0.74 & $2.1^{\mathrm{g}}$ \\
\hline InSb & 45.9 & $47^{\mathrm{a}}$ & 47 & 0.74 & $1.7^{\mathrm{g}}$ \\
\hline $\mathrm{ZnS}$ & 74.46 & $74.32^{\mathrm{c}}$ & 90 & 0.47 & $5.0^{\mathrm{g}}$ \\
\hline $\mathrm{CdS}$ & 71.45 & $69^{\mathrm{a}}$ & 69 & 0.48 & $4.9^{g}$ \\
\hline $\mathrm{CdTe}$ & 45.71 & $47^{\mathrm{a}}$ & 47 & 0.49 & $3.2^{\mathrm{g}}$ \\
\hline $\mathrm{ZnSe}$ & 64.7 & $64.7^{\mathrm{d}}$ & 75 & 0.53 & $4.9^{g}$ \\
\hline $\mathrm{ZnTe}$ & 52.8 & $51^{\mathrm{a}}$ & 59 & 0.53 & $4.0^{\mathrm{g}}$ \\
\hline CdSe & 54.4 & $53^{\mathrm{a}}$ & 60 & 0.54 & $4.2^{\mathrm{g}}$ \\
\hline
\end{tabular}

TABLE 2: Comparison of calculated (using (1)) and measured values of the bulk moduli of III-V and II-VI compounds. ${ }^{\mathrm{a}}[4],{ }^{\mathrm{b}}[5],{ }^{\mathrm{c}}[6]$, $\mathrm{d}[7]$.

\begin{tabular}{lccc}
\hline Compound & $B_{0}$ cal. $(\mathrm{GPa})$ & $B_{0}$ exp. $(\mathrm{GPa})$ & $(\%)$ \\
\hline $\mathrm{GaP}$ & 74.19 & $87^{\mathrm{a}}$ & 14.7 \\
$\mathrm{InP}$ & 66.6 & $67^{\mathrm{a}}$ & 0.59 \\
$\mathrm{AlSb}$ & 58.8 & $58^{\mathrm{a}}$ & 1.3 \\
$\mathrm{GaAs}$ & 73.23 & $74.8^{\mathrm{b}}$ & 2 \\
$\mathrm{InAs}$ & 59.15 & $60^{\mathrm{a}}$ & 1.4 \\
$\mathrm{GaSb}$ & 56.7 & $57^{\mathrm{a}}$ & 0.5 \\
$\mathrm{InSb}$ & 45.9 & $47^{\mathrm{a}}$ & 2.3 \\
$\mathrm{ZnS}$ & 74.46 & $74.32^{\mathrm{c}}$ & 0.1 \\
$\mathrm{CdS}$ & 71.45 & $69^{\mathrm{a}}$ & 3.4 \\
$\mathrm{CdTe}$ & 45.71 & $47^{\mathrm{a}}$ & 2.7 \\
$\mathrm{ZnSe}$ & 64.7 & $64.7^{\mathrm{d}}$ & 0 \\
$\mathrm{ZnTe}$ & 52.8 & $51^{\mathrm{a}}$ & 3.4 \\
$\mathrm{CdSe}$ & 54.4 & $53^{\mathrm{a}}$ & 2.5 \\
\hline
\end{tabular}

moduli values compared with those of experimental scale and Cohen [4] are given in Table 1. It may conclude that the present bulk moduli calculated in a different way than the definition of Cohen are in good agreement with the experimental values as seen in Figure 1, and exhibit the same chemical trends as those found in the values derived from the experimental scale or Cohen theory as seen in Table 1. The results of these calculations are in agreement with Cohen's [4] results and very near to results of experimental scale.

Some systematic behavior in the results of the calculated values has been noticed. For the II-VI compounds, the differences between the experimental and calculated values are less than $4 \%$ except for $\mathrm{ZnSe}$ where the coincidence is happened and the discrepancies are three times as larger for III-V compounds semiconductors, as shown in Table 2. The calculation estimates are larger than the measured values for the III-V compounds, and the tendency is similar for the II-VI com-

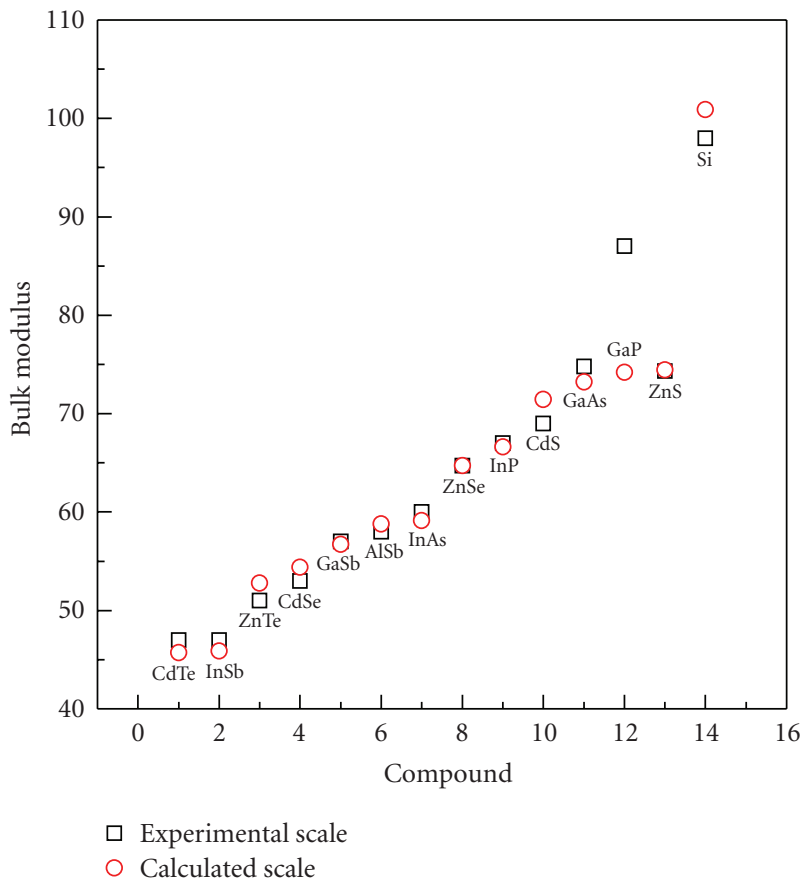

FIGURE 1: The experimental and our calculated bulk modulus scales by using formula (1) for different semiconductors.

pounds. It can be argued that the calculation-empirical differences are the same order as differences between reported measured values, and their chemical trends are real [4]. In conclusion, the empirical model obtained for the bulk modulus gives results in good agreement with the results of other scales.

\section{REFERENCES}

[1] M. L. Cohen, "Pseudopotentials and total energy calculations," Physica Scripta, vol. T1, pp. 5-10, 1982. 
[2] J. C. Phillips, Bonds and Bands in Semiconductors, Materials Science and Technology Series, Academic Press, San Diego, Calif, USA, 1973.

[3] W. A. Harison, Electronic Structure and the Properties of Solids: The Physics of the Chemical Bond, General Publishing, Toronto, Ontario, Canada, 1989.

[4] M. L. Cohen, "Calculation of bulk moduli of diamond and zinc-blende solids," Physical Review B, vol. 32, no. 12, pp. 7988-7991, 1985.

[5] P. K. Lam, M. L. Cohen, and G. Martinez, "Analytic relation between bulk moduli and lattice constants," Physical Review B, vol. 35, no. 17, pp. 9190-9194, 1987.

[6] J. C. Jamieson and H. H. Demarest Jr., "A note on the compression of cubic ZnS," Journal of Physics and Chemistry of Solids, vol. 41, no. 9, pp. 963-964, 1980.

[7] J. G. Collins, G. K. White, J. A. Birch, and T. F. Smith, "Thermal expansion of ZnTe and HgTe and heat capacity of HgTe at low temperatures," Journal of Physics C: Solid State Physics, vol. 13, no. 9, pp. 1649-1656, 1980.

[8] K. Strössner, S. Ves, C. K. Kim, and M. Cardona, "Dependence of the direct and indirect gap of AlSb on hydrostatic pressure," Physical Review B, vol. 33, no. 6, pp. 4044-4053, 1986.

[9] R. G. Humphreys, U. Rössler, and M. Cardona, "Indirect exciton fine structure in $\mathrm{GaP}$ and the effect of uniaxial stress," Physical Review B, vol. 18, no. 10, pp. 5590-5605, 1978.

[10] I. M. Tsidilkovski, Band Structure of Semiconductors, Pergamon Press, Oxford, UK, 1982. 

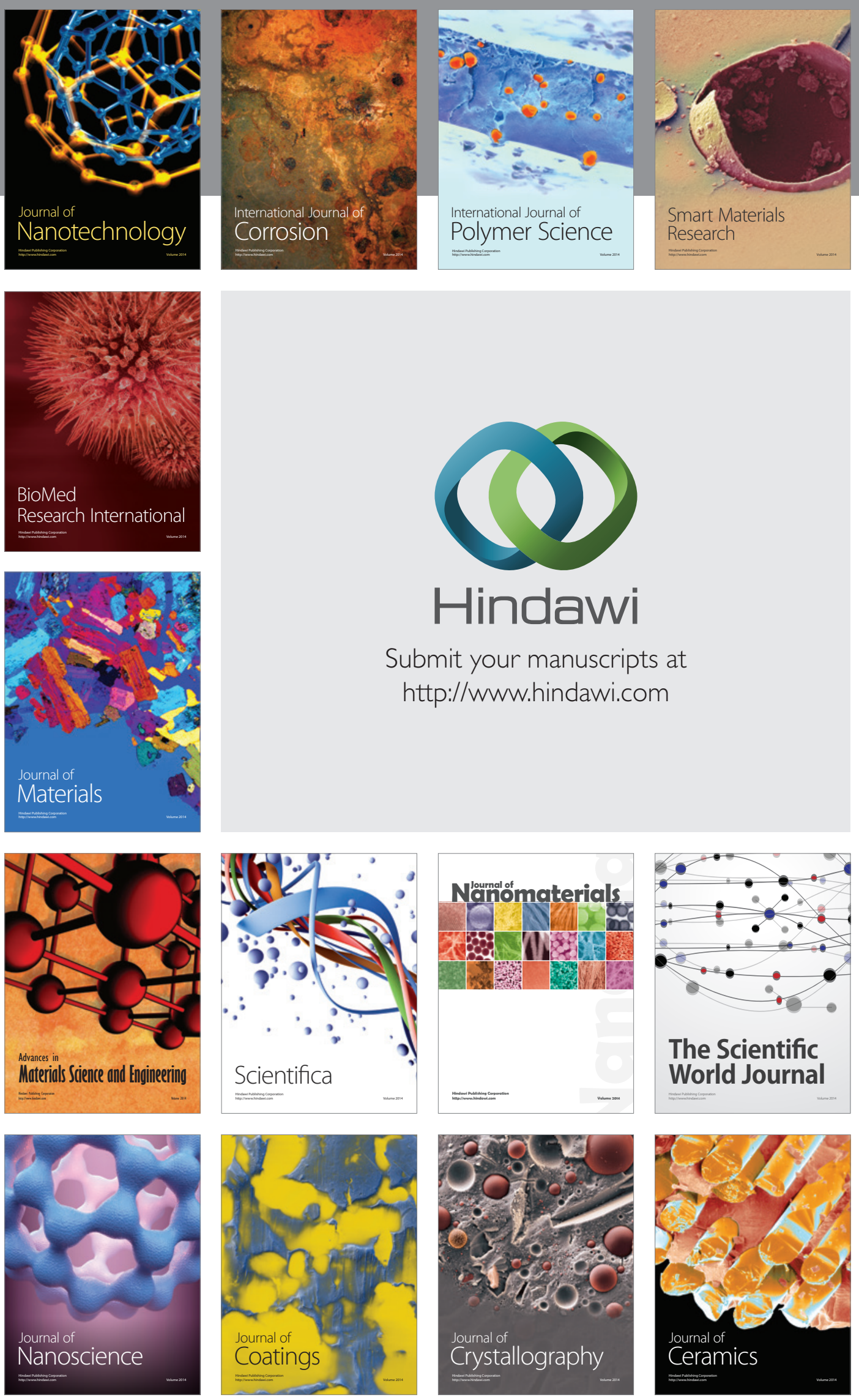

The Scientific World Journal

Submit your manuscripts at

http://www.hindawi.com

\section{World Journal}

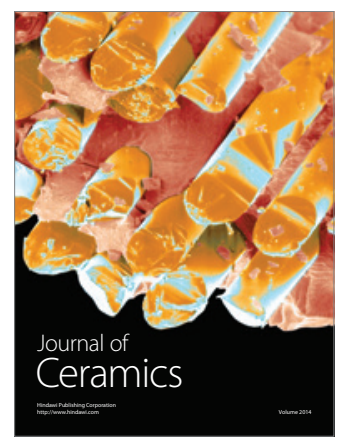

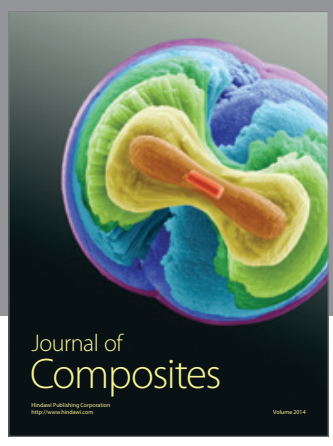
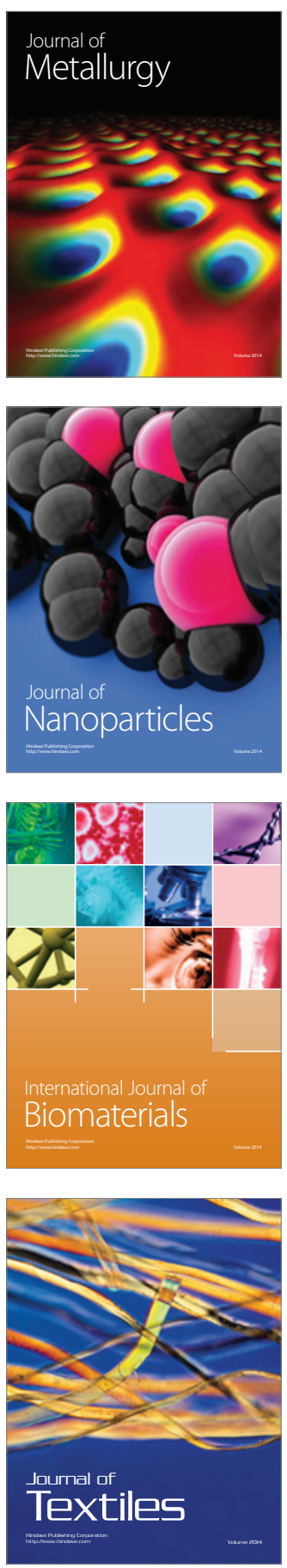